\title{
IDEOLOGIA, ESCOLA E CONHECIMENTO: \\ DA REPRODUÇÃO DO CURRÍCULO OCULTO ÀS POSSIBILIDADES DE SUPERAÇÃO A PARTIR DA PEDAGOGIA HISTÓRICO-CRÍTICA
}

\author{
Mariângela Machado de Castro ${ }^{1}$ \\ André Luiz Sena Mariano ${ }^{2}$
}

\begin{abstract}
RESUMO
O presente artigo, de natureza ensaística, procura problematizar a utilização do conceito de currículo oculto, relacionando-o às discussões alusivas ao termo ideologia. Nesse sentido, reconhece, em primeiro lugar, que essa dimensão do currículo define-se pelas aprendizagens sociais consideradas relevantes e que configuram-se como necessárias à manutenção do sistema capitalista. A partir desse reconhecimento, apresenta as potencialidades e limites do currículo oculto, especialmente no que tange às relações entre educação e trabalho e com vistas às suas relações com o conceito de ideologia. Segue problematizando o engessamento que o currículo oculto causa quando é utilizado como artefato explicativo da realidade social, uma vez que nega o caráter contraditório da sociedade capitalista ao enfatizar, somente, o movimento de reprodução das desigualdades sociais. O texto finaliza apostando no potencial da Pedagogia Histórico-Crítica como um caminho mais fecundo não só para a problematização teórica da realidade, mas como arcabouço que permite a organização de elementos teórico-práticos da vida social.

Palavras-Chave: Currículo Oculto, Ideologia, Pedagogia Histórico-Crítica
\end{abstract}

\section{IDEOLOGY, SCHOOL AND KNOWLEDGE: HIDDEN CURRICULUM OF REPRODUCTION TO POSSIBILITIES OF OVERCOMING FROM PEDAGOGY HISTORICAL-CRITICAL}

\begin{abstract}
This article, by essayistic nature, aims to discuss the use of the concept of hidden curriculum, linking it to discussions alluding to the term ideology. In this sense, recognizes, first, that this dimension of the curriculum is defined by social learning deemed relevant and are configured as necessary to maintain the capitalist system. From that recognition, it has the potential and limits of the hidden curriculum, especially in regard to relations between education and work and with a view to its relations with the concept of ideology. Follow questioning the immobilization the hidden curriculum because when it is used as an explanatory device of social reality as it denies the contradictory nature of capitalist society by emphasizing only the reproduction of movement of social inequalities. The article concludes by betting on the potential of the Historical-Critical Pedagogy as a more fruitful way not only to the theoretical questioning of reality, but as a framework that allows the organization of theoretical and practical elements of social life. Keywords: Hidden Curriculum; Idoelogy; Pedagogy Historical-Critical
\end{abstract}


O presente artigo, de natureza ensaística, procura problematizar a utilização do conceito de currículo oculto, relacionando-o às discussões alusivas ao termo ideologia. Nesse sentido, reconhece, em primeiro lugar, que essa dimensão do currículo define-se pelas aprendizagens sociais consideradas relevantes e que se configuram como necessárias à manutenção do sistema capitalista. Não se trata, portanto, de restringir seu potencial aos aspectos cognitivos, mas de problematizar suas ações com vistas à formação de sujeitos obedientes e resignados à ordem social (SILVA, 2009).

A partir desse reconhecimento, o artigo procura, num primeiro momento, apresentar as potencialidades e limites do currículo oculto, especialmente no que tange às relações entre educação e trabalho e com vistas às suas relações com o conceito de ideologia. Segue problematizando o engessamento que o currículo oculto causa quando é utilizado como artefato explicativo da realidade social, uma vez que nega o caráter contraditório da sociedade capitalista ao enfatizar, somente, o movimento de reprodução das desigualdades sociais. O texto finaliza apostando no potencial da Pedagogia Histórico-Crítica, apoiada em Dermeval Saviani, como um caminho mais fecundo não só para a problematização teórica da realidade, mas como arcabouço que permite a organização de elementos teóricopráticos da vida social.

\section{O CONCEITO DE IDEOLOGIA NA TRADIÇÃO MARXISTA}

De acordo com Chauí (2004), o termo ideologia surgiu pela primeira vez em 1801 na obra intitulada Elementos de Ideologia, de Antoine Destutt de Tracy. O filósofo francês criou este termo para defender a necessidade de uma nova ciência das ideias - durante a Revolução Francesa - com o intuito de tratá-las como fenômenos naturais que exprimiam a relação do corpo humano, como organismo vivo, com o meio ambiente, possibilitando o conhecimento das indagações a respeito das ideias humanas e de como elas se desenvolviam.

Contudo, em 1812, Napoleão Bonaparte declarou em um discurso o sentido pejorativo do termo ideologia, invertendo a imagem que os ideólogos tinham de si mesmos. Assim, a ideologia, que inicialmente designava uma ciência natural da aquisição, pelo homem, das ideias calcadas sobre o próprio real, passa a designar, daí por diante, um sistema de ideias condenadas a desconhecer sua relação com o real (CHAUÍ, 2004, p.10 - 11). É certo que depois de Bonaparte o termo ideologia voltou a ser empregado por importantes nomes, tais como Comte e Durkheim. Entretanto, a discussão aqui presente será direcionada por outra concepção de ideologia.

Segundo Eagleton (1997), é possível definir a ideologia a partir de seis maneiras diferentes. A primeira delas é considerar o termo como processo material geral de produção de ideias, crenças e valores na vida social, abrangendo as relações entre esses signos e os processos do poder político. Outra definição diz respeito a ideias e crenças, tanto verdadeiras quanto falsas, que representam as condições e experiências de vida de um grupo específico, dominante.

A terceira definição proposta por Eagleton (1997) trata-se da ascensão e legitimação dos interesses de tais grupos sociais defronte os interesses opostos. Já a quarta indicada pelo autor, conserva a ênfase referida na definição anterior, porém, restringindo-a às atividades de um poder social dominante. Logo, a quinta definição sugere que a ideologia significa ideias e crenças que ajudam a legitimar os interesses de uma classe dominante, envolvendo a distorção e a dissimulação. E, por fim, a sexta definição de ideologia incide sobre as falsas crenças, considerando-as procedentes da estrutura material do conjunto da sociedade como um todo. Em síntese, Eagleton (1997) confirma que o 
termo ideologia faz referência a questões de poder, legitimando o domínio de uma classe social e residindo entre as lutas de poder existentes. Pois, se não há valores e crenças que 'não' sejam relacionados com o poder, então o termo ideologia corre o risco de expandirse até o ponto de desaparecer (EAGLETON, 1997, p. 20-21).

O intelectual alemão Karl Marx conservou o termo pejorativo de ideologia proposto por Napoleão Bonaparte, afirmando que o ideólogo é aquele que inverte as relações entre as ideias e o real. Chauí (2004) afirma que, para Marx, é importante analisar a história dos homens já que a ideologia se restringe a uma visão distorcida desta história. Além disso, a autora declara que Marx, embora tenha feito críticas a alguns aspectos da filosofia hegeliana, conservou muitos elementos propostos por Hegel. Sendo assim,

A reflexão de Marx sobre a questão da ideologia passou a se desenvolver criticamente a partir do ajuste de contas com Hegel. Foi na Crítica do direito público hegeliano, escrita em Kreuznach, em meados de 1843, que Marx se insurgiu contra o modo de Hegel interpretar a relação do Estado com a sociedade civil (KONDER, 2002, p.30).

A interpretação feita por Hegel era a de que o Estado fosse o local onde a razão predominava. Assim, Konder (2002) narra que Marx compreendeu a construção ideológica criada a partir de sua crítica à interpretação de Friedrich Hegel. O filósofo socialista constatou que Hegel se referiu às tensões provocadas entre sociedade civil e Estado, entretanto, seu pensamento não era amplo e permanecia restrito a uma única visão. Assim sendo, Marx teceu análises que foram além das formadas por Hegel.

Nesta tradição, a história é o desenvolvimento das forças produtivas pela ação da luta de classes. Também é concebida como o modo a partir do qual os homens produzem suas condições reais de existência, bem como suas relações sociais. Associando estas relações sociais ao trabalho, Konder (2002) declara que a burguesia chegou a decompor a própria força humana de trabalho em item de compra e venda na medida em que foi reduzindo tudo à mercadoria. Corroborando essa ideia, Chauí (2004) apresenta que o ser humano é uma mercadoria, tornando-se um valor capitalista. Ademais, a autora afirma que a origem do capital é o trabalho não pago, uma vez que

[...] a mercadoria não é uma coisa (como aparece), mas trabalho social, tempo de trabalho. E que não é qualquer tempo de trabalho, mas tempo de trabalho não pago, portanto a mercadoria oculta o fato de que há exploração econômica. Estamos longe, agora, do aparecer social estamos diante do modo de constituição real do sistema capitalista. Passamos de algo abstrato e imediato a algo concreto e mediato: passamos da mercadoria como coisa à mercadoria como valor de uso e de troca, destes à mercadoria como tempo de trabalho social, deste à mercadoria como trabalho não pago e, portanto, à forma de relação social entre o proprietário privado dos meios de produção e o trabalhador por ele explorado (CHAUÍ, 2004, p.20).

Outro elemento mantido por Marx - da concepção filosófica hegeliana - é a afirmação de que a realidade é histórica e, portanto, passível de reflexão. No entanto, indaga-se a respeito da dialética marxista, pois sendo ela materialista, acaba colocando como imperativo o fato de não poder haver uma reflexão sem que isso leve à transformação da realidade. 
Nesse sentido, torna-se necessário explicar - conforme Chauí (2004) - que Marx se refere à maneira como os homens produzem e reproduzem suas condições materiais reais de existência, ou seja, ele se refere à matéria social. Para o filósofo socialista Leandro Konder, as classes sociais em luta são o motor que move a história, constituindo-se em relações sociais que se fazem classe de indivíduos em suas atividades econômicas, políticas e culturais. Logo, o que realmente interessa na dialética marxista é a divisão social do trabalho, bem como a relação entre os próprios homens. Em relação ao trabalho, Konder (2002) expõe que este

[...] é a primeira atividade do ser humano como ser humano. É pelo trabalho que passa a existir a contraposição sujeito/objeto. Os animais também produzem, mas o que os guia é o instinto, são as necessidades naturais mais imediatas; os homens, contudo, podem produzir mesmo em condições nas quais não estão pressionados por necessidades físicas imediatas (e, de fato, assegura Marx, só produzem 'humanamente' quando estão liberados dessas pressões).

O trabalho é a atividade pela qual o ser humano se criou a si mesmo; pelo trabalho ele transforma o mundo e se transforma (KONDER, 2002, p.35).

É oportuno ressaltar que Marx analisou os fatores positivos e negativos do trabalho, uma vez que este se tornou bastante desagradável para muitos trabalhadores, resultando em uma desumanização. Devido às transformações ocorridas, Chauí (2004) enfatiza que o trabalhador passou a ser uma "coisa" chamada força de trabalho que recebe uma "coisa" que se chama salário. Consequentemente, a divisão social do trabalho produz e é produzida pela desigualdade social. Nesta divisão, temos os proprietários privados do capital e a massa dos assalariados, sendo que estes últimos dispõem somente de sua força de trabalho.

Contudo, Konder (2002) ressalta que - na visão de Marx - a separação entre o trabalho material/manual e o trabalho espiritual/intelectual é necessária para que se torne concreta a divisão social do trabalho. Em uma determinada época, descreve Santomé (1995), tornou-se imprescindível diferenciar os tipos de homem necessários para a sociedade, divididos entre os que serviriam para estudar/pensar e os que trabalhariam manualmente, executando àquilo que fora pensado. Na obra $A$ ideologia alemã - expõe Konder (2002) - feita pelos amigos Marx e Engels, o tema ideologia foi retomado e os autores afirmaram que no momento em que a divisão social do trabalho decompôs os trabalhos material e intelectual, respectivamente, surgiram as ideologias. E, como resultado dessa separação, surgiu uma classe que dominaria outra, mantendo seus privilégios por meio do Estado e da ideologia. Sendo assim, Chauí pondera que:

Nasce agora a ideologia propriamente dita, isto é, o sistema ordenado de ideias ou representações e das normas e regras como algo separado e independente das condições materiais, visto que seus produtores - os teóricos, os ideólogos, os intelectuais - não estão diretamente vinculados à produção material das condições de existência. E, sem perceber, exprimem essa desvinculação ou separação através de suas ideias (CHAUÍ, 2004, p.26).

A divisão social do trabalho determina a formação das classes sociais e a separação entre sociedade (instituições) e política (Estado). Assim, na sociedade capitalista, as relações entre os indivíduos se dão pela compra e venda da força de trabalho, e, por meio de ideologias, cada classe se vê "livre" diante do contrato de trabalho. Essas ideias 
formadas, como declara Chauí (2004), produzem uma inversão da realidade. De forma mais clara, as relações sociais surgem como se fossem "naturais" e não como consequência das ações dos homens. Ou seja, a inversão concretiza-se no momento em que se assumem os resultados de um processo como se fossem seu começo, os efeitos pela causa. A ideologia caracteriza-se também pela inversão da realidade. As ideias criadas representam a aparência social, considerando-as como independentes da realidade, invertendo-a. Isto significa que uma ideologia sempre possui uma base real, só que essa base está de pontacabeça: é a aparência social (Ibid., p.40).

É correto afirmar, de acordo com Santomé (1995), que os grupos dominantes elaboram legitimações com o intuito de assegurarem seu poder. Estas legitimações - que se tornam aceitáveis para a sociedade - são postas para que as pessoas possam aprender o que fora estabelecido pela classe dominante, uma vez que esta classe impõe seus próprios interesses. Apple (2006) descreve que a ideologia interessa-se pela legitimação, pois há uma aceitação social a partir das justificativas das ações de um determinado grupo. $\mathrm{O}$ autor ainda acrescenta que não se pode tratar a ideologia como um fato simples. A ideologia, como já evidenciado, é um dos modos utilizados pela classe que detém o poder para exercer sua dominação, sendo que essa dominação é feita de maneira a que os dominados não a percebam. É função da ideologia ocultar a existência do conflito de classes para que a dominação não seja percebida. Em poucas palavras, a ideologia oculta que se origina da luta de classes com a finalidade de servir uma determinada classe social.

Inegavelmente, a ideologia é uma ferramenta de dominação de classe que se concretiza de maneira bastante eficaz, uma vez que é resultado da luta de classes e que tem por função esconder a existência dessa luta. Podemos acrescentar que o poder ou a eficácia da ideologia aumenta quanto maior for sua capacidade para ocultar a origem da divisão social em classes e a luta de classes (CHAUÍ, 2004, p.34). Ademais, é correto afirmar que a ideologia, a julgar pela forma como é concebida, parece ser algo que não tem história e, a partir dessa falsa premissa, ela produz uma história imaginária, a fim de legitimar a dominação de uma classe predominante.

Dessa maneira, a história narrada é sempre a do ponto de vista dos vencedores (detentores do poder), os quais mantêm sua hegemonia fazendo com que os vencidos interiorizem a ideia de que são apenas pacientes dessa história. Então, há uma hegemonia dominante na sociedade, caracterizando-se em uma das funções da ideologia. Tal conceito é denominado por Gramsci e consiste na manutenção das ideias dominantes. Pode-se afirmar que a ideologia incide na criação de ideias universais a partir da modificação das ideias particulares da classe que detém o poder, sendo que a hegemonia é o poder utilizado pelo grupo que domina. Esclarecendo melhor essa ideia, Chauí descreve - sobre a hegemonia - que

Este fenômeno da conservação da validade das ideias e valores dos dominantes, mesmo quando se percebe a dominação e mesmo quando se luta contra a classe dominante mantendo sua ideologia, é que Gramsci denomina de hegemonia. Uma classe é hegemônica não só porque detém a propriedade dos meios de produção e o poder do Estado (isto é, o controle jurídico, político e policial da sociedade), mas ela é hegemônica, sobretudo porque suas ideias e valores são dominantes, e mantidos pelos dominados até mesmo quando lutam contra essa dominação (CHAUI, 2004, p.42).

De tal modo, a ideologia nasce para servir aos interesses de uma classe por meio de normas, regras e preceitos, transformando suas ideias em ideias universais que são 
distribuídas em um conjunto de instituições sociais para sua implantação. É criado um conjunto lógico de normas de conduta, como apresenta Chauí (2004), que norteiam os membros da sociedade sobre a forma de como devem agir e pensar. A ideologia apresenta a função de explicar racionalmente as diferenças existentes - sociais, políticas e culturais em uma sociedade dividida, todavia, sem conferir estas diferenças à divisão de classes.

As instituições utilizadas para sua implantação e disseminação são encarregadas de permitir a reprodução das relações sociais e das ideias universais que ficam sob o controle da classe dominante, sendo elas: família, escola, igreja, partidos políticos, imprensa, meios de comunicação, Estado, entre outras. Conforme afirma Santomé (1995), os grupos hegemônicos definem suas ideias consideradas importantes para viver e trabalhar na sociedade, partindo, sobretudo, de uma racionalidade econômica repleta de interesses, legitimando seu domínio. Estes grupos não definem apenas ideias, mas definem também o conhecimento. E, dessa maneira, a instituição social que se destaca - enquanto local de apropriação de conhecimento - e que merece ser analisada é a escola.

\section{IDEOLOGIA, ESCOLA, COTIDIANO: AÇÕES DO CURRÍCULO OCULTO}

Diante do que fora exposto, pode-se constatar que a dinâmica da sociedade capitalista acontece sob a dominação de classe, isto é, da dominação dos que detêm o poder e o controle da propriedade dos recursos materiais sobre aqueles que possuem somente sua força de trabalho. Essa maneira de como a economia está organizada sobrevém em tudo aquilo que ocorre nas demais esferas sociais, como na educação, por exemplo. Portanto, com toda a certeza, há uma relação estrutural entre economia e educação.

Confirmando essa certeza, Santomé (1995) assegura-nos que uma instituição educativa mantém uma estreita relação com as demais esferas da sociedade, não podendo ser compreendida de maneira descontextualizada. Nesse sentido, a escola é uma construção histórica e social e, consequentemente, não é uma instituição neutra, uma vez que

Os projetos curriculares, os conteúdos do ensino, os materiais didáticos, os modelos organizacionais das escolas e liceus, as condutas dos alunos e do professorado, etc., não são algo que possamos contemplar como questões técnicas e neutras, à margem das ideologias e do que acontece em outras dimensões da sociedade, tais como a económica, a cultural e a política. Pelo contrário, grande parte das decisões que se tomam no âmbito educativo, e dos comportamentos que aí se geram, é condicionada ou afetada por acontecimentos e peculiaridades dessas outras esferas da sociedade e atinge todo o seu significado sob uma perspectiva de análise que tenha em conta essa intercomunicação (SANTOMÉ, 1995, p.13 $14)$.

O sistema educativo costuma ser pensado a partir de ideologias com o escopo de inculcar nos alunos - e também nas famílias - seus papéis fixos na sociedade, já que reflete a economia capitalista. Aliás, o processo de educação não apenas coloca os indivíduos em seus respectivos papéis, como também os socializa de modo a fazer com que aceitem seus papéis como legítimos. Há nas escolas, indubitavelmente, a função seletiva do ensino centrada no currículo por disciplinas, visando a selecionar agentes para preencher posições econômicas e sociais em uma sociedade desigual. Desse modo, o conteúdo cultural é utilizado como um filtro para a estratificação econômica, expandindo o conhecimento técnico. Pode-se dizer que o conhecimento que chega às escolas é selecionado e 
organizado conforme um conjunto de princípios e valores que representam determinadas visões de mundo.

Outrossim, é o conceito de hegemonia que permite ver o campo social como um espaço onde os grupos dominantes se veem forçados a recorrer a um empenho constante de convencimento ideológico para sustentar sua dominação. Com efeito, é precisamente através desse esforço de convencimento que a dominação econômica se transforma em hegemonia cultural (SILVA, 2009, p.46). Há uma intrínseca relação entre a organização da economia e a maneira como o currículo está constituído, lembrando que a escola reflete as relações sociais do local de trabalho por meio do currículo formal e do currículo oculto. E, segundo essa afirmação, convém ressalvar que a escola ensina um currículo oculto que parece estar basicamente voltado à manutenção da hegemonia ideológica das classes mais poderosas. Assim, a reprodução mais ampla da sociedade é assegurada através da reprodução da cultura dominante, pois tal cultura apresenta superioridade e valor social.

As escolas são agentes da hegemonia - pelo ensino oculto - e recriam a desigualdade não só "produzindo pessoas" como também "reproduzindo o conhecimento". É correto afirmar que o conhecimento reproduzido pela escola tem intenções variadas, ou seja, se destina a pessoas diferentes e de classes diferentes. Conclui-se, então, que a distribuição do conhecimento é desigual e que somente alguns grupos tem acesso e outros não, uma vez que as instituições escolares apresentam uma função ideológica. Em outras palavras, as escolas legitimam (abertamente ou não) os conhecimentos, os símbolos, as formas econômicas e sociais e as ideologias. E isso nos

[...] permite que comecemos a ver como a sociedade reproduz a si mesma, como perpetua suas condições de existência por meio da seleção e transmissão de determinados tipos de capital cultural dos quais uma complexa, mas desigual, sociedade industrial depende e como mantém a coesão entre classes e indivíduos pela propagação de ideologias que acabam por sancionar os arranjos institucionais existentes e que podem causar estratificação desnecessária e desigualdade em primeiro lugar (APPLE, 2006, p.98).

É por isso que as escolas ensinam princípios e regras e servem aos interesses econômicos a partir de uma ideologia eficaz. Pode-se assegurar que a ideologia é uma forma de falsa consciência que distorce a realidade social e serve aos interesses da classe dominante, isto é, são ideias que se criam sobre a realidade e que não lhe correspondem de fato. Nisso, as escolas parecem contribuir significativamente para a desigualdade por distribuírem determinados tipos de conhecimento, já que o controle do conhecimento é um fator importante para a expansão da preponderância ideológica. Por isso, deve-se reconhecer os interesses sociais que, frequentemente, orientam a seleção e a organização do currículo.

Michael Apple (2006) alega que as escolas organizam-se conforme os interesses pelo poder, selecionando determinados tipos de alunos e distribuindo o conhecimento de maneira desigual, contribuindo para a organização de uma sociedade estratificada pela classe e pela capacidade de cada indivíduo. Em consonância a isso, Dubet (2008) assegura que nenhuma escola conseguiu se proteger das desigualdades sociais e que seu sistema seleciona os melhores alunos, reproduzindo ainda mais a desigualdade. E, para que uma sociedade seja justa, é fundamental contribuir para o benefício daqueles que estão em desvantagem, sendo que não é isso o que ocorre nas instituições de ensino. Contudo, de acordo com Apple (2006), as escolas parecem exercer seu papel (bem ou mal), 
favorecendo uma ordem social e econômica complexa e estratificada por meio de seus currículos.

O campo do currículo, mais especialmente do que em outras áreas educacionais, tem sido dominado por uma perspectiva que poderia ser chamada de 'tecnológica', pelo fato de que o maior interesse que orienta seu trabalho envolve encontrar o melhor conjunto de meios para atingir fins educacionais previamente escolhidos (APPLE, 2006, p.82).

Esse autor afirma que o currículo escolar responde a recursos ideológicos, pois quando se pensou em currículo fora elaborada uma teoria que teve como alicerce a diferenciação de objetivos educacionais em termos de funções particulares da vida adulta. Desse modo, o currículo deveria enfatizar as afirmações hegemônicas, totalmente inerentes aos processos moral e político, e, que envolve concepções ideológicas, políticas e bastante pessoais de valiosas atividades educacionais. Além do mais, um de seus principais componentes é o fato de influenciar outras pessoas - nomeadamente, os alunos (Ibid., p.157).

Em vista disso, há uma estreita relação entre a educação e o crescimento tecnológico, uma vez que o nível desse crescimento é dependente do nível de escolarização. A escola deve produzir uma força de trabalho diversificada e qualificada, uma vez que é vista como propulsora do avanço social e pessoal por meio da capacidade do indivíduo. Existe um modelo de desempenho acadêmico pautado no controle técnico e na eficiência, no qual a escola tornou-se uma importante instituição para a reprodução cultural e econômica. Como resultado disso há uma forte seleção dos melhores e mais "capacitados", fazendo com que os demais indivíduos aceitem seus papéis na sociedade. Santomé (1995) atém-se a dizer que há uma tese, estabelecida pelos que detêm o poder, de que quanto mais se escolariza mais se aumenta a produtividade econômica de um país. A partir disso, o sistema educativo se conduz para socializar cada aluno de acordo com as características da organização ocupacional adulta. De modo geral,

A intenção prioritária dos processos de ensino-aprendizagem nas escolas do ensino básico e secundário é preparar os alunos e alunas para que amanhã, como futuros trabalhadores e trabalhadoras, possam integrar-se sem grandes conflitos no interior da estrutura hierárquica que define o modelo de relações laborais da economia capitalista, relações essas às quais subjaz um modelo de desigualdade entre uns membros e os outros, segundo o lugar que se ocupa, de dono ou não dos meios de produção, e o nível hierárquico atribuído a cada posto de trabalho na estrutura ocupacional. Os objetivos que vão determinar a atuação dos proprietários dos meios de produção são os de procurar obter o máximo benefício, independentemente das injustiças que isso possa acarretar (SANTOMÉ, 1995, p.70).

As instituições de ensino, afirma Santomé (1995), estruturam-se conforme o domínio da esfera econômica, distribuindo meritocraticamente cada sujeito a partir de diferentes modalidades e estratégias curriculares. É imprescindível afirmar que os profissionais da escola não atuam na reprodução sempre de forma consciente, uma vez que o currículo oculto vigora no âmbito da instituição. Além disso, não se torna visível em uma escola quem e quando se decide o que deve ser ensinado, permitindo com que a escola se julgue neutra em relação à economia. 
Neste contexto, os grupos sociais dominantes estabelecem um conhecimento válido e defendem uma ideologia para servir de sustentação, pautando-se em uma racionalidade econômica. Deste modo, é adequado dizer que o currículo torna-se centralizado, feito a partir "de cima". Pode ser afirmado que há uma negligência quanto à maneira como se selecionam os conteúdos, os objetivos, entre outros aspectos, isolando tais seleções do poder econômico. Isso porque, na perspectiva do currículo oculto, a consideração de que o econômico determina em última instância a vida social parece não existir.

Com relação a isso, Santomé (1995) acrescenta que é unicamente a economia que determina que competências, hábitos, valores, normas e conhecimentos é necessário que os alunos e alunas adquiram (Ibid., p.71).

Devido a este fato, novamente pode-se apontar a forte relação - que não deve ser interpretada como dependência única e exclusiva - entre as instituições escolares e a estrutura econômica. Isto é, há uma relação entre a escola e o mundo do trabalho como se pode observar a seguir:

[...] a 'função latente' economicamente mais importante da vida escolar parece ser a seleção e geração de atributos e de significados normativos que capacitam o indivíduo a ter uma chance de retorno econômico. Como vimos, está intimamente ligado, também, ao papel cultural da escola na maximização da produção de conhecimento técnico. Pelo fato de a escola ser a única grande instituição que se situa entre a família e o mercado de trabalho, não é estranho que, tanto historicamente quanto hoje, determinados significados sociais que tragam benefícios diferenciais sejam distribuídos nas escolas (APPLE, 2006, p.88).

Certamente, a escola desempenha a função de manutenção das relações sociais e econômicas vigentes, uma vez que parece funcionar como um aparelho ideológico do Estado. Santomé (1995) sublinha que a instituição escolar é, dentre todos os aparelhos ideológicos, aquele que exerce com domínio a função de reprodução dos ideais capitalistas, pois dispõe de tempo para tal intento e, inclusive, é gratuita para todos da sociedade. $\mathrm{Ou}$ seja, a escola recebe a criança, independentemente de sua classe social, obrigando-a a frequentar seu ambiente por determinado tempo e a prepara, classificando-a para desempenhar sua função na sociedade e, muitas vezes, abre mão da formação omnilateral do indivíduo. Decerto, todas as práticas e experiências vividas no interior da escola contribuem para reforçar as relações de poder existentes na sociedade. Logo, é através da reprodução das qualificações e da reprodução da submissão às regras da ordem estabelecida, ou seja, à ideologia dominante, que se consegue a reprodução da força de trabalho (SANTOMÉ, 1995, p.60).

Trata-se, portanto, de entender que a escola tem efeitos importantes enquanto instituição de reprodução cultural, social e econômica, pois toda criança frequenta uma escola. Desde o início da escolarização ensina-se às crianças as regras pré-estabelecidas para se enquadrar em um determinado padrão, para que possam se adaptar à ordem vigente. Estas regras ensinadas são essenciais ao longo da permanência na instituição, pois a experiência da pré-escola servirá como alicerce para os anos escolares que virão. E como uma das funções da escola é a socialização, essa se faz também por meio da aprendizagem de normas e definições das interações sociais.

A noção de "trabalho" está presente na escola desde a educação infantil, pois há uma diferenciação entre "hora de brincar" e "hora de trabalhar". A escolarização faz com que se criem diferentes tipos de indivíduos que correspondam às exigências do mercado de trabalho e contribui para a adequação individual a uma ordem social, econômica e política. 
Assim, os alunos aprendem a como trabalhar e a desempenhar seus papéis relativamente alienantes. E, com o intuito de se preparar o aluno para a vida do trabalho, o currículo passa a se diferenciar e a servir aos objetivos econômicos e ideológicos, pois

Se se considera que um grupo de alunos possui futuros membros de uma classe profissional e administrativa, as escolas e o currículo parecem se organizar em torno de conceitos como flexibilidade, escolha, pesquisa, etc. Se, por outro lado, a destinação provável dos alunos for a de trabalhadores sem habilitação ou semi-habilitados, a experiência escolar tende a enfatizar a pontualidade, a organização, a formação de hábitos, etc. Essas expectativas são reforçadas pelos tipos de currículo e testes que as escolas dão e pelos rótulos afixados a diferentes tipos de alunos (APPLE, 2006, p.105).

Devido a esta diferenciação do currículo, torna-se mais fácil a transição da sala de aula para o "escritório", já que desde os primeiros anos de escolarização os alunos desenvolvem hábitos relacionados ao trabalho. É de modo implícito - por meio do currículo oculto - que as práticas cotidianas em uma escola ganham um significado que correspondem a uma sociedade industrializada de economia capitalista. Isto explica o fato de que tudo o que se passa em uma escola (relações sociais existentes, normas, interações, tarefas, ensino etc.) correspondem aos objetivos que esta instituição pretende alcançar, segundo a lógica capitalista.

Sendo assim, a categoria trabalho compreende, desde muito cedo, a vida de cada sujeito. Santomé (1995) também enfatiza a divisão entre a diversão e o trabalho na educação infantil. Ele afirma que os alunos escolhem os materiais para se divertirem somente no "tempo livre" e que eles preferem terminar as atividades a tempo para poder brincar. É oportuno ressaltar que as atividades de trabalho costumam ser obrigatórias e, quando não cumpridas, penalizadas. As atividades de diversão - fundamentais para o desenvolvimento infantil - não são controladas e avaliadas pelos educadores, já que são realizadas por menos tempo e após as atividades obrigatórias. De certa maneira, os alunos associam tais diferenças nas atividades, descobrindo o valor de cada tarefa. Um exemplo disso é que os alunos contam sobre as atividades de trabalho quando são indagados sobre o que aprenderam na escola.

Como resultado, os alunos aprendem o "papel de estudante" por meio das interações vivenciadas no cotidiano escolar. Torna-se possível comprovar, mais uma vez, que há certa correlação entre as exigências da esfera econômica (que determina em última instância a vida humana) e a vida escolar. Pois, é através da interação social registrada diariamente nas salas de aula que se vão construindo os significados dos objetos e das situações, que se vão formando as subjetividades e se vão criando as habilidades, conhecimentos e destrezas que cada sociedade privilegia e valoriza (SANTOMÉ, 1995, p.83). As experiências escolares cotidianas, sobretudo em escolas infantis, reforçam normas e costumes considerados indispensáveis em uma sociedade. Aos poucos, tacitamente, as novas gerações são preparadas conforme as necessidades de um modelo econômico de produção e de relações de trabalho.

Santomé (1995) acrescenta que, de maneira geral, as instituições escolares possuem uma estética inconfundível, podendo ser conferida uma uniformidade em todas elas. O que se ensina na escola é bastante importante, porém, a maior preocupação dos professores é de estabelecer a ordem na sala de aula, fazendo com que seus alunos permaneçam em seus lugares e que saibam esperar, levantar o dedo, fazer uma fila, silenciar, realizar todas as atividades, responder perguntas quando necessário, entre outros pontos. Como 
consequência, as instituições escolares, bem como sua organização e seu currículo devem ser analisados em relação a outros lugares e atividades sociais, uma vez que produzem efeitos sobre os indivíduos.

São os lugares de trabalho nas empresas capitalistas que impõem o seu modo de atuação às escolas. A hierarquia que ali reina, os valores, normas, competências que caracterizam a divisão do trabalho existente na sociedade capitalista são o espelho no qual se mira a instituição escolar. Esta imita-as, reprodu-las, e contribui assim para que os seus estudantes, no futuro, possam aceitar os imperativos económicos, sociais e culturais da economia capitalista. É deste modo que o grupo dos estudantes aprende a funcionar apenas por recompensas externas, as notas, num primeiro momento, e, mais tarde, os salários; é assim que se habituam a ser avaliados, a obedecerem, a fazerem o que se lhes manda, a serem competitivos, a serem produtivos... (Ibid., p.71).

De acordo com isto, a escola torna-se uma "empresa" de prova, seleção e distribuição, classificando, hierarquizando e rotulando os alunos com vistas ao mercado de trabalho. Produz, assim, os "bons" e "maus" alunos, distinguindo os mais capacitados e aptos para cargos elevados no futuro. E, basicamente, torna-se uma eficiente selecionadora dos indivíduos. Pode ser destacado que a escola é, na maioria das vezes, a instituição capaz de rotular seus alunos, permitindo com que tais rotulações se perpetuem na vida de cada indivíduo. O uso de determinados rótulos sociais proporciona um impacto sobre os alunos que os aceitam como naturais, aproximando-se tal fato do currículo oculto. Portanto, Apple (2006) alega que a rotulação ocupa um lugar sutil, embora seja indispensável e necessária no processo de classificação. Ademais, as escolas - agentes do controle social e da reprodução social e econômica - necessitam se preocupar com a eficiência e, dentre outras formas, a rotulação se faz importante para se realizar este objetivo.

Em relação às provas, exames, testes e/ou avaliações, pode-se concluir que são palavras existentes durante toda a vida de escolarização e, também, na vida dos adultos, já que se transformaram em uma força legitimadora na disposição burocrática da sociedade atual. Por conseguinte, Santomé (1995) explicita que os exames realizados nas escolas perpetuam as formas de opressão (econômica e social) sobre os indivíduos que já iniciam a vida escolar em desvantagem, ocasionando o seu fracasso. Cabe lembrar que o exame - um instrumento bastante utilizado pelos professores - é temido por todos os alunos, ainda mais pelos que falham.

Os resultados dos testes servem para distribuir as pessoas na estrutura social de acordo com suas capacidades intelectuais, legitimando as vitórias e os fracassos no interior das escolas. Constata-se, desse modo, que a finalidade prioritária da socialização dos alunos na escola é prepará-los para sua incorporação ao mundo do trabalho. Para realizar tal fim, a escola conduz e consolida o individualismo, a competividade e a falta de solidariedade. Há uma ideologia que reforça as diferenças sociais e determina a reprodução. Nesse sentido, a escola torna-se um poder ativo, que, muitas vezes, acaba por legitimar as forças econômicas e as ideologias vinculadas a ela. Logo, a escola também colabora para o surgimento das desigualdades sociais, pois se sabe que há uma desigualdade real no ponto de partida. Isto é instrumentalizado pelo currículo oculto, a escola estimula a conformidade a ideias nacionais e convenções sociais ao mesmo tempo em que mantém desigualdades socioeconômicas e culturais.

No que concerne à ação da escola, esta desenvolve o processo de classificação, de exclusão das minorias e de diferenciação voltados para o mundo do trabalho. De certa 
maneira, aceitam-se as "aparências" de um currículo, permitindo com que seja mais eficaz a função de socializar as novas gerações na desigualdade, em que os mais desfavorecidos parecem aceitá-la passivamente. Santomé (1995) argumenta que a pessoa aceita suas "incapacidades" a partir do instante em que seu insucesso for revelado, uma vez que não existe outra saída. O fato é que as demais instituições sociais existentes não se responsabilizam pelo insucesso escolar.

As crianças e até mesmo os jovens da classe desfavorecida só podem encarar o fracasso como resultado. Assim, completa-se o ciclo da reprodução cultural. É essencialmente através dessa reprodução cultural, por sua vez, que as classes sociais se mantêm tal como existem, garantindo o processo de reprodução social. (SILVA, 2009, p.35). Dessa maneira, a escola se torna um local de recriação da desigualdade, aonde os efeitos negativos se perpetuarão devido a todos os mecanismos utilizados em seu cotidiano para que prevaleça a ideologia dominante.

Há uma inerente relação entre ideologia e instituição escolar. Diante disso, percebese como a sociedade reproduz a si mesma e como perpetua suas condições de existência por meio de determinadas ideias que sustentam o sistema econômico vigente. Neste sentido, o que se procura salientar é a forma como o currículo oculto, quando aplicado para a compreensão da realidade, acaba por limitar as possibilidades escolares, restringindo-a a uma função de reprodução das desigualdades sociais.

O currículo oculto impede a consideração de uma instituição que, ao mesmo tempo em que atua na inculcação e na reprodução dos valores hegemônicos, possa funcionar como um espaço que potencialize aos desfavorecidos a aquisição dos mesmos instrumentais dados à classe dominante, reconhecendo, assim, o caráter contraditório da instituição escolar.

Faz-se necessário superar tal ideia. É preciso ir além do currículo oculto para que o movimento das contradições seja notado. Pode-se evidenciar que a natureza da prática pedagógica implica uma desigualdade real e uma igualdade possível. Por isso, é importante tornar válido, conforme diz Saviani (2005), que não se trata apenas de eleger entre relações autoritárias ou democráticas no cotidiano escolar. Os aspectos essenciais das relações sociais que se ocultam já foram evidenciados. Trata-se, portanto, de promover a união do trabalho desenvolvido nas salas de aula com o processo de democratização da sociedade para que, o conceito que apresenta uma única forma de ação da instituição escolar, o currículo oculto, seja superado.

\section{À GUISA DE CONCLUSÃO: BUSCANDO APONTAR POSSIBILIDADES A PARTIR DA PEDAGOGIA HISTÓRICO-CRÍTICA}

Ao fim do estudo aqui delineado, pode-se afirmar que foi na primeira metade do século XIX que o capitalismo se consolidou como um modo de produção, o qual não exigia do operário um esforço do pensamento. Com efeito, após o desenvolvimento da maquinaria, bem como o auge da ciência e da técnica, passou-se a exigir do operário uma qualificação da força de trabalho. Surgiu, então, o sistema escolar institucionalizado, uma vez que o capitalismo exigiu uma crescente capacidade intelectual de todos os indivíduos. Por conseguinte, as escolas adotaram os padrões de eficiência e produtividade das fábricas e utilizaram o currículo para a diferenciação e a seleção dos indivíduos com inteligência e capacidade, mantendo as relações hegemônicas. Logo, ampliaram-se as desigualdades devido à distribuição diferenciada do conhecimento, fazendo com que ocorresse uma competição - em busca de notas, resultados etc. -, e que os alunos que "fracassassem" 
nesse jogo fossem excluídos socialmente. E isso, com toda a certeza, não está próximo de ser uma escola justa.

Sendo assim, a escola atua conformando sujeitos para a sociedade capitalista, especialmente reconhecendo o seu caráter contraditório e inerente, qual seja: preparar, ao mesmo tempo, sujeitos para trabalhos intelectuais (para posições de destaque) e sujeitos para trabalhos manuais. Com isso, é possível apontar, a forte relação existente entre escola e mundo do trabalho. Apple (2006) profere que a semelhança que pode ser estabelecida é a de que a escola é a "fábrica" e o aluno é o "produto" nela gerado.

De acordo com a lógica capitalista, uma pessoa que não recebeu um título em uma instituição de ensino não está capacitada para ganhar um bom salário. Santomé (1995) assegura que questões políticas, éticas e filosóficas estão presentes no desenvolvimento de um currículo. Ainda, as instituições de ensino são criadas e recriadas pelas práticas que as sustentam. Para analisar o sistema educativo é imprescindível atentar-se tanto para o currículo explícito (formal) quanto para o currículo oculto. O currículo formal indica as normas legais, os conteúdos mínimos obrigatórios, os projetos educativos, entre outros elementos. Já o currículo oculto faz referência aos conhecimentos que se dão por meio das interações existentes na escola.

É possível constatar que as instituições educativas estão estruturadas com o intento de preparar seus alunos para que, futuramente, possam desempenhar seus respectivos papéis na sociedade, seguindo os interesses dos grupos sociais dominantes. Deste modo, a educação tende a socializar os alunos aspirando contribuir para a reprodução das relações sociais existentes. Por isso, não se pode dizer que o âmbito escolar é neutro e, consequentemente, o currículo também não é neutro. Porém, é válido destacar que há o conceito de dialética afirmado por Marx, o qual apresenta a contradição como motor da produção da realidade. Ou seja, há uma unidade dos contrários, fazendo com que algo seja, ao mesmo tempo, ele mesmo e o seu contrário, não existindo separadamente. Como resultado, pode-se declarar que o materialismo dialético privilegia o movimento e as contradições reais.

Marx e Engels pretendiam superar o capitalismo, acentuando suas contradições e desenvolvendo suas possibilidades a fim de transformar a sociedade. Para tal, seria necessário tecer uma crítica à instituição escolar para, assim, mudá-la. Dessa maneira, compreender o currículo oculto é essencial para que a reprodução seja percebida. Não obstante, faz-se necessário ir além do currículo oculto.

Saviani (2005) expõe que a educação deve se constituir como uma força que tem por papel tornar mais sólido os vínculos sociais, garantindo a integração de todos os indivíduos no corpo social. Tal força necessita ser homogeneizadora de modo com que ocorra uma equalização social. Além do mais, como o autor discute sobre a questão da marginalidade, a educação, para além do currículo oculto, deve atuar como um instrumento de correção. Cabe dizer que a análise da História é sempre histórica, apresentando a realidade como o centro dessa apreciação. Então, torna-se possível olhar a instituição escolar como uma realidade histórica com o intuito de modificá-la por meio da atuação humana, pois a ação coletiva leva à transformação.

O autor faz referência à teoria da curvatura da vara, proposta por Lênin, para que se possa compreender que há outros modos de se conceber a educação. É certo que a educação tornou-se um aparato da classe dominante. No entanto, revela-se a importância de se criar mecanismos para superar esta "única" visão referente à escola. A educação, para o autor, relaciona-se dialeticamente com a sociedade. E, nessa perspectiva, sempre haverá um vínculo entre educação e sociedade. Lembrando que, ainda que existam críticas à escola, não se descobriu um mecanismo melhor que atendesse a função de ensinar a ler e a 
escrever. Deve-se compreender o sistema educativo como a passagem da desigualdade real à igualdade possível. Mas, é preciso considerar que a educação não é capaz de, sozinha, mudar a sociedade.

Diante disso, Saviani (2005) traz a concepção denominada Pedagogia HistóricoCrítica, a qual articula teoria e prática e supera tanto os limites das "pedagogias nãocríticas" quanto os das "teorias crítico-reprodutivistas". Esta concepção sugerida compromete-se definitivamente em colocar a educação a serviço da transformação das relações de produção. Além disso, em sua obra Escola e Democracia, o autor discorre sobre cinco etapas do processo educativo. A primeira delas é partir da prática social para que se obtenha a problematização (segunda etapa) das questões relevantes. Logo, a instrumentalização torna-se a terceira etapa do processo, uma vez que esta pauta-se na assimilação de instrumentos teóricos e práticos necessários à solução dos problemas levantados. Já a quarta etapa consiste na catarse, ou seja, no instante da concreta incorporação dos instrumentos culturais e transformados em elementos ativos. Por fim, como quinta etapa, tem-se a própria prática social para que seja transformada.

Ressalta-se que Saviani (2005) diferencia política de educação, pois tratam-se de práticas distintas, embora sejam inseparáveis. A relação política, segundo ele, se trava entre antagônicos, apresentando como único objetivo "vencer". Já a educação configura-se como uma relação entre não-antagônicos, pois educador e educando estão em busca de interesses semelhantes. Por isso, o professor não precisa vencer, mas "convencer" o aluno. Apesar de se diferenciarem, toda prática educativa tem sua dimensão política e, como tal, toda prática política possui sua dimensão educativa. Ademais, tais relações entre política e educação só podem ser compreendidas enquanto manifestações sociais determinadas.

A concepção de uma nova proposta pedagógica - Pedagogia Histórico-Crítica procura elucidar a estrutura contraditória a partir da qual funciona a escola na sociedade capitalista, permitindo, deste modo, distinguir que, por meio dessas contradições, é possível unir a escola aos movimentos reais que tendem a transformar a sociedade. Consequentemente, é preciso apontar a relevância da compreensão das complexas interrelações existentes entre a escola e os aspectos da reprodução cultural, social e econômica.

É possível observar que o cotidiano nas salas de aula deixa clara a existência de uma forte relação entre as instituições de produção capitalistas e a instituição escolar. Logo, nota-se que o currículo sofre influência de ideologias capitalistas. Eagleton (1997) destaca que há muitas acepções de ideologia, todavia, este termo se refere às questões de poder, legitimando o domínio de uma classe social. Indubitavelmente, as relações entre os discursos ideológicos e os interesses sociais são complexas e variáveis. Além disso, a ideologia contribui ativamente para a constituição de interesses sociais.

Segundo essa concisa definição de ideologia, pode-se perceber os interesses e as relações de poder que envolvem a seleção de determinados conhecimentos em detrimento de outros. Contudo, o poder não é sempre notável como controle econômico e, devido a isso, ele é exercido naturalmente por meio das instituições, favorecendo a reprodução e a legitimação da desigualdade existente. Assim sendo, o sistema econômico está diretamente ligado ao sistema cultural, pois o conhecimento é um poder dos que controlam tais sistemas.

É afirmado tanto por Santomé (1995) quanto por Saviani (2005) que, sozinha, a escola não pode alterar em nada a luta pela transformação das estruturas de produção e das atuais relações sociais. Entretanto, somente a partir de uma mudança nas estruturas de produção é que transformações poderiam ser alcançadas nas instituições escolares. Faz-se necessário examinar criticamente não apenas como os conhecimentos são adquiridos pelos 
alunos, mas, sobretudo, como certos aspectos da vida social são apresentados na escola como conhecimentos objetivos.

A partir de uma educação crítica os alunos serão capazes de questionar aquilo que é considerado normal, como os conhecimentos, atitudes e comportamentos e, portanto, desocultar o currículo oculto e fazer com que ele perca sua eficácia. Torna-se essencial que se determine o que cada um tem direito, fazendo com que a escola assuma outro papel e que trate os "vencidos" de maneira justa. É certo que para uma sociedade ser justa, precisase colaborar em benefício dos sujeitos que se encontram em desvantagem. Portanto, a tarefa primordial de uma instituição de ensino deve ser a de educar para formar sujeitos capazes de conduzir suas próprias vidas, reconhecendo, como foi mostrado, que os homens a produzem sob condições que não escolheram. Para isso, é imprescindível que se tenha uma educação crítica, cônscia dos limites e, também, das possibilidades. Em virtude disso, pode-se almejar que se contribua a favor do desaparecimento das injustiças sociais.

\section{Referências}

APPLE, Michael W. Ideologia e currículo. 3 ed. - Porto Alegre: Artmed, 2006.

CHAUÍ, Marilena. O que é ideologia. São Paulo: Brasiliense, 2004. Coleção Primeiros Passos.

DUBET, François. O que é uma escola justa? São Paulo: Cortez, 2008.

EAGLETON, Terry. Ideologia. São Paulo: Boitempo, 1997.

KONDER, Leandro. A questão da ideologia. São Paulo: Companhia das Letras, 2002.

MARX, K; ENGELS, F. Textos sobre Educação e Ensino... Campinas: Navegando, 2011.

PINTO, Álvaro Vieira. Sete lições sobre educação de adultos. 14 ed. São Paulo: Cortez, 2005.

SANTOMÉ, Jurjo T. O curriculum oculto. Porto - Portugal: Porto Editora, 1995.

SAVIANI, Dermeval. Escola e democracia. $36^{a}$ ed. Campinas - SP: Autores Associados, 2005.

SILVA, Tomaz T. Documentos de identidade: uma introdução às teorias do currículo. 3 ed. - Belo Horizonte: Autêntica, 2009.

THOMPSON, Edward P. A miséria da teoria: ou o planetário de erros. Rio de Janeiro: Zahar Editores, 1981.

\footnotetext{
${ }^{1}$ Graduada em Pedagogia pela Universidade Federal de Alfenas (UNIFAL-MG), Mestranda junto ao Programa de Pós-Graduação em Educação da Universidade Federal de São Carlos (PPGE/UFSCar). E-mail: mariangela.sgs@gmail.com

${ }^{2}$ Doutor em Educação pela Universidade Federal de São Carlos (UFSCar). Professor Adjunto do Instituto de Ciências Humanas e Letras da Universidade Federal de Alfenas (UNIFAL-MG). E-mail: alsmariano@yahoo.com.br

Recebido: junho-15 Aprovado: outubro-15
} 